\title{
FATORES DETERMINANTES DA ESTRUTURA DE CAPITAL DE EMPRESAS BRASILEIRAS DE TECNOLOGIA
}

\author{
DETERMINANT FACTORS OF THE CAPITAL STRUCTURE OF BRAZILIAN \\ TECHNOLOGY COMPANIES
}

\section{Camila Freitas Sant'Ana}

Tarcísio Pedro da Silva

Fundação Regional de Blumenau - FURB, Blumenau, Santa Catarina, Brasil

\section{RESUMO}

O objetivo do estudo foi identificar os fatores determinantes da estrutura de capital de empresas brasileiras de tecnologia. A pesquisa caracterizou-se como descritiva, documental e quantitativa, composta por 21 empresas dos setores de comunicações, telecomunicações e indústria digital, conforme classificação da Revista Exame. A análise estabeleceu-se no período de 2009 a 2013 por meio de regressão de dados em painel. Os resultados indicam que a taxa de crescimento do capital e o tipo de controle apresentam uma relação positiva com o endividamento geral e de longo prazo. Entretanto, observou-se que o tamanho da empresa, a rentabilidade e o tipo de capital apontam uma relação negativa com a estrutura de capital.

Palavras-chave: Estrutura de capital; Desempenho Econômico-financeiro; Endividamento; Empresas de Tecnologia.

\begin{abstract}
The purpose of this study is to identify determinant factors of the capital structure of Brazilian technology companies. The research was characterized as descriptive, document and quantitative, consisting of 21 companies in the communications, telecommunications and digital industry, according to the Exame magazine ranking. The analysis was established from 2009 to 2013 using panel data regression. The results indicate that the growth rate of capital and control type have a positive relationship with the general and long-term debt. However, it was found that company size, profitability and type of capital point to a negative relationship with the capital structure.
\end{abstract}

Keywords: Capital structure; Financial-economic performance; Indebtedness; Techology companies.

Manuscript first received/Recebido em: 10/06/2015 Manuscript accepted/Aprovado em: 28/10/2015

Address for correspondence / Endereço para correspondência

Camila Freitas Sant'Ana, Fundação Regional de Blumenau, Blumenau, Santa Catarina, Brasil, fone: (47) 3321-0565 E-mail: mila-internacional@hotmail.com

Tarcísio Pedro da Silva, Fundação Regional de Blumenau - FURB, Blumenau, Santa Catarina, Brasil E-mail: tarcisio@furb.br 


\section{INTRODUÇÃO}

Um dos principais determinantes que envolvem o desenvolvimento de um país no contexto socioeconômico trata-se da inovação tecnológica (Jones \& Willians, 2000). Neste cenário, destaca-se que essa inovação tecnológica está atrelada aos gastos ligados à pesquisa e ao desenvolvimento de produtos $(\mathrm{P} \& \mathrm{D})$, que é evidenciada nos países mais ricos e desenvolvidos que apresentam um parque industrial mais avançado e, consequentemente, contribui para um melhor desenvolvimento da infraestrutura tecnológica e competitividade econômica no comércio mundial (Jensen, Menezes-Filho \& Sbragia, 2004).

Devido a essa importância que a inovação tecnológica representa, a criação e a evolução das empresas de tecnologia, que trabalham com os avanços da informática, biotecnologia, robótica, mecânica fina, aeroespacial, eletrônica e microeletrônica, fazem com que o nível tecnológico cresça e mude rapidamente, estimulando a concorrência empresarial e a movimentação da economia como um todo (Marcovicth, Santos \& Dutra, 1986).

Isso indica que, cada vez mais com o aumento do desenvolvimento de novas tecnologias de informação e/ou comunicação, os empresários e gestores devem ficar atentos às necessidades de aprimoramentos ou uso de mais instrumentos, técnicas ou métodos para fins gerenciais, que visam dar suporte para o processo de tomada de decisões mais assertivas (Fischmann \& Zilber, 1999).

Assim, estudos como o de Lach e Schankerman (1989) pesquisaram a interação dinâmica entre $P \& D$, o investimento de capital e a performance no mercado de ações nos Estados Unidos e, evidenciaram que o investimento nas empresas tecnológicas é afetado seja pelos gatos em $\mathrm{P} \& \mathrm{D}$, bem como também pelo investimento em capital físico, considerando que este é influenciado por diversas forças externas, como a própria mudança tecnológica, que impactam diretamente no planejamento de investimento no longo prazo.

Essas evidências criam a expectativa de que o endividamento das empresas de tecnologias também seja explicado por fatores que possam demonstrar o comportamento do nível de endividamento das empresas do setor. Assim, diante do contexto apresentado, tem-se a seguinte questão-problema de pesquisa: "quais são os fatores determinantes da estrutura de capital de empresas brasileiras de tecnologia?".

Assim, para atingir a proposta de estudo tem-se o objetivo de identificar os fatores determinantes da estrutura de capital de empresas brasileiras de tecnologia.

O estudo justifica-se por evidenciar a apresentação do constructo teórico frente aos fatores determinantes do endividamento das empresas de tecnologia, que comportam as áreas de telecomunicações, comunicações e indústria digital. Tendo em vista que alguns estudos buscaram tentar retratar o comportamento do endividamento das empresas de tecnologia, como a pesquisa de Marcon, Grzebieluckas, Mello e Muller (2007), que investigou o comportamento da estrutura de capital e a performance de empresas brasileiras, argentinas e chilenas, com o intuito de verificar se $o$ endividamento e a rentabilidade em média entre os países, é significativamente diferente. O resultado encontrado foi que o Brasil apresentou maior endividamento, menor rentabilidade dos ativos, e menor retorno do patrimônio líquido. 
O período de análise da pesquisa é de cinco anos, compreendidos entre os anos de 2009 e 2013, devido à disponibilidade das informações para realizar o estudo, considerando que diversos pesquisadores utilizaram este período para representar a análise dos dados (Marcon et al., 2007; Nakamura, Martin, Forte, Carvalho Filho, Costa e Amaral, 2007). Desta forma, Assaf Neto (2012) ressalta que este período determinado, está dentro do padrão de três a cinco anos da realização de uma análise que possibilite a comparação temporal e o acompanhamento da evolução de indicadores evidenciados na pesquisa.

Com isso, esse estudo contribui por analisar quais são os fatores que determinam o endividamento das empresas brasileiras de tecnologia, que apresentam diferentes contextos de controle externo e interno.

Posteriormente, após a seção introdutória, que apresenta a sustentação para a realização da pesquisa, segue-se estruturada com o referencial teórico que estabelece o embasamento da literatura a metodologia da pesquisa, a apresentação da análise dos dados e as discussões dos resultados e, finalizando, são feitas as considerações finais, seguida das referências bibliográficas utilizadas.

\section{REFERENCIAL TEÓRICO}

Para embasar o presente estudo, o referencial teórico aborda os principais aspectos que fundamentam a temática problematizada, relacionados ao endividamento, estrutura de capital, desempenho econômico e financeiro, bem como as teorias relevantes.

O levantamento dos estudos e pesquisas relacionadas ocorreu nas bases de dados bibliográficos da SPELL - Scientific Periodicals Electronic Library, da Scopus Document Search, da Science Direct, da Jstor, da Redalyc - Red de Revistas Científicas de América Latina y el Caribe, España y Portugal e do Portal de Periódicos Capes.

\subsection{Determinantes da Estrutura de Capital}

O nível de endividamento das empresas está atrelado à forma com que essas se financiam, porém quanto a esta questão, destaca-se na literatura a continuidade nas investigações na teoria de finanças.

Tendo em vista que, na teoria tradicional aponta-se que a estrutura leva à maximização do valor à empresa, enquanto que Modigliani e Miller (1958) salientam que essa estrutura de capital não influencia o valor da empresa.

Muito se discute sobre a estrutura de capital desde que ganhou ênfase após o aporte teórico elaborado por Modigliani e Miller (1958), no qual os autores consideram sob a hipótese de mercado eficiente que não existe relativamente uma estrutura de capital ótima. Hipótese complementada por Modigliani e Miller (1963), por meio da preconização de que a estrutura de capital pode vir a sofrer com a influência dos benefícios fiscais, como da dedução de juros no cálculo da renda tributável, ambos resultantes do endividamento, mas que não necessariamente indicam que as empresas devam utilizar-se do máximo possível de dívida em sua estrutura de capital.

Entretanto, posteriormente, Miller (1977) contradiz a questão evidenciando que o conhecimento do comportamento das taxas de juros deveria servir de base para o 
estabelecimento de uma estrutura de capital ótima e, assim, então, aumentar o valor da empresa por meio do uso de dívidas se podem ser dedutíveis das rendas tributáveis.

Para Camargos e Barbosa (2003), a Teoria ou Hipótese de Eficiência do Mercado parte da premissa de que os preços dos títulos acionários das organizações devem refletir todas as informações importantes para o processo de tomada de decisões gerenciais, incumbindo em um mercado perfeito, sem a ocorrência de assimetria informacional.

Neste contexto, como não existe mercado eficiente na concepção de Modigliani e Miller (1958), o estudo realizado por Fama (1970), analisando o conjunto de preços e retornos do mercado de ações abordados em estudos que enfocavam esta temática, classificou o nível de atenção do mercado como de forma fraca, quando consideravam o custo histórico no mercado de capitais. Já na segunda classificação do nível de atenção denominou-se semiforte, devido a verificação da rapidez com qual os preços passavam a ser reajustados, dando maior ganho de conteúdo informacional aos seus usuários.

A última classificação determinou-se como forma forte, em virtude da prevalência de uma maior preocupação dos gestores com o gerenciamento das informações, do qual se evidenciou a implantação de ações para diminuir os efeitos de assimetria de informação e tornar os preços negociados no mercado mais correntes do que baseado em custo histórico.

Passado uma série de proposições sobre a estrutura de capital, Myers (1984) determina a divisão da estrutura de capital sob a perspectiva de duas correntes teóricas: Static Trade Off e a Pecking Order Theory. Considerando, a teoria do Trade Off ressalta que as organizações devem mirar em uma estrutura de capital ótima, que possibilite a maximização dos benefícios e minimização dos custos referentes ao endividamento. Porém, em relação à teoria de Pecking Order não volta-se diretamente ao nível ótimo de capital, mas sim ao estabelecimento de uma ordem de modo hierárquico quanto às preferências de tipos de financiamento.

Assim, relacionando-se ao modelo Trade Off, David, Nakamura e Bastos (2009) ressaltam que a inferência do aspecto tributário impacta principalmente no benefício da dívida em relação ao patrimônio líquido.

Enquanto, Myers (1977) aponta a existência de uma lacuna dentro da teoria, na condição de predizer possíveis motivações para que uma empresa obtenha mais financiamentos em relação às demais.

Com base no Trade Off, destaca-se quanto aos pagamentos de dividendos, que os mesmos ocorrem de acordo com os ajustes realizados em relação às metas de remuneração, buscando um nível ideal de endividamento, considerando como uma medida defensiva a redução nos pagamentos de dividendos quando houver instabilidade financeira (Myers, 1984).

Já, em relação ao modelo Pecking Order Theory, Myers e Majluf (1984) enfatizam a hierarquia de fontes de financiamento previamente destacada por Modigliani e Miller (1958), considerando como ordem de preferência primeiramente a retenção de recursos gerados internamente, emissão de dívida e emissão de novas ações. Mas, que por outro enfoque pode ser compreendida como um processo de endividamento perigoso, porém evitaria problemas de assimetria, uma vez que tudo está sobre seu controle (Myers, 2001). 
Para Rajan e Zingales (1995), no contexto da Pecking Order Theory, empresas com maior capacidade de gerar resultados positivos apresentam menor nível de endividamento. Assim, como empresas pouco lucrativas, tendem a ser mais endividadas pelo fato de necessitarem utilizar maior proporção de recursos de terceiros, mas considerando que cada empresa possui a sua estrutura ótima de capital (Brealy \& Myers, 2006).

Desta forma, a Teoria da Pecking Order consiste na opção das organizações de utilizarem primeiramente da possibilidade do autofinanciamento e, somente posteriormente, caso necessário, recorre-se ao financiamento externo (Vieira, Novo, 2010).

Assim, denota-se na teoria de finanças que o endividamento altera-se em função do desequilíbrio que advém dos fluxos de caixa internos e das possibilidades de investimento, que não são contraídas pela tentativa de estabelecimento de uma estrutura de capital ótima, mas sim de uma necessidade de recursos externos para a operacionalização da empresa (Shyam-Sunder\& Myers, 1999).

\subsection{Desempenho Econômico-Financeiro}

Há diversos fatores que podem influenciar no grau de endividamento de uma empresa que, de acordo com Bastos e Nakamura (2009), pode ser tanto o desempenho econômico quanto o financeiro, ou ainda também, por exemplo, o próprio ambiente em que a organização possa estar inserida. Desta forma, para o estabelecimento dos determinantes da estrutura de capital discorre-se que estes não estão restritos somente aos fatores específicos das empresas, mas como também aos seguintes determinantes como: o nível de tangibilidade, o tamanho, a rentabilidade, o risco, a oportunidade de crescimento, o grau de imposto de renda e os benefícios fiscais.

Assim, neste impasse da estrutura de capital com o desempenho econômico e financeiro, subsequentemente surge no debate teórico questões relacionadas à alavancagem e ao crescimento econômico, partindo mais para uma análise ou projeção do desempenho futuro da empresa, considerando a políticas do investimento, gerenciamento do fluxo de caixa, bem como perspectivas e oportunidades futuras do mercado de capitais (Lang, Ofek\& Stulz, 1996).

Neste cenário de análise do desempenho, Fama (1998) retoma a discussão relacionada à eficiência de mercado quanto às anomalias e oportunidades de ganhos para as empresas no longo prazo, dos quais, para Resende (2012), os principais agentes interessados são junto a stakeholders, shareholders, bem como também analistas de mercado e pesquisadores.

Entretanto, Anthony e Govindarajan (2001) e Matarazzo (2008), destacam que a literatura dispõe de diversos modelos para apreciação da avaliação do desempenho das organizações, em virtude de que a avaliação quando referida à situação financeira decorre do resultado econômico, e quando referida à avaliação não financeira volta-se à análise de produtos, satisfação dos clientes, dentre outros.

Deste modo, para estabelecer-se a avaliação de desempenho econômico e financeiro das empresas, primeiramente deve-se iniciar com base nos dados consolidados pelas demonstrações contábeis, preparadas em consonância aos princípios contábeis, normas e legislação vigente, com a finalidade de refletir com transparência o real valor econômico do negócio (Martinez, 1999). 
Para Silva (2012), a apreciação da avaliação do desempenho econômico e financeiro da empresa refere-se à uma análise detalhada das informações financeiras e econômicas colocadas ao dispor pela empresa, divulgadas nas demonstrações de resultados do exercício, e também em eventos internos e externos que afetam ou possam a vir afetar a organização financeiramente. Assim, a base inicial para evidenciação do desempenho econômico e financeiro concentra-se nas demonstrações contábeis, das quais se possibilita informações quanto à capacidade de liquidez, rentabilidade, bem como sobre a estrutura de capital (Damodaran, 1997; Miltersteiner, 2003).

Gitman e Joehnk (2005) evidenciam que as demonstrações de resultado são essenciais para análise da empresa, uma vez que permite aos investidores formarem uma opinião sobre os resultados operacionais e as condições financeiras nas quais a empresa se encontra. Outrossim, a apreciação desses relatórios possibilita detectar os pontos positivos e negativos que ocorrem na área financeira que, porém, devem ser interpretados de forma adequada, para que possam ser tomadas as ações corretivas cabíveis (Groppelli\& Nikbakht, 2006).

Partindo deste pressuposto, Zilber e Fischmann (2002) e Ferreira e Macedo (2011) discorrem que a avaliação do desempenho econômico-financeiro é de extrema importância para fornecer informações relevantes para o processo de tomada de decisão mais propício e coerente ao planejamento estratégico e ao aumento da eficiência da organização. Neste sentido, Macedo, Santos e Silva (2006) complementam que a avaliação do desempenho auxilia no direcionamento das ações da organização frente ao ambiente competitivo do mercado.

Outra possibilidade disponível com a avaliação de desempenho econômico e financeiro para os gestores compreende a disponibilidade de realização de comparações de índices financeiros entre empresas ou grupo de empresas, podendo de acordo com seu objetivo, por exemplo, evidenciar o comportamento histórico, presente ou projeção futura para determinado evento (Helfert, 2000).

Borba (2005) e Macedo, Santos e Silva (2006) destacam como indicadores de desempenho econômico e financeiro as medidas de lucratividade, rentabilidade e valor de mercado. Já Yang (2012) ressalta ainda os índices de crescimento das vendas, retorno sobre o investimento, vendas, patrimônio líquido, lucro por ação, concentração e participação de mercado, medidas de qualidades dos produtos, eficácia do marketing, eficiência tecnológica, etc.

Para Matarazzo (2008), a utilização de índices de análise econômico-financeiros possibilita reconhecer o desempenho da empresa de maneira real, além de projetar suas perspectivas. Nesta concepção, Hajj (2005) discorre que a análise desses índices econômico-financeiros extraídos das demonstrações contábeis, mais especificamente do Balanço Patrimonial (BP) e da Demonstração de Resultado (DRE), requer uma apreciação crítica e pormenorizada do seu significado, decompondo todas as partes relacionadas, que também pode se estabelecer por meio da combinação de indicadores para análise.

\subsection{Estrutura de Capital e Desempenho Econômico-financeiro}

Estudos destacam a análise da estrutura de capital com base nas teorias de Trade Off e Pecking Order e evidenciam o nível de endividamento das empresas, bem como corroboram com a inferência dos determinantes da estrutura de capital que podem refletir no desempenho econômico-financeiro das organizações. 
Como forma de análise da estrutura de capital, diversas pesquisas como as de Remmers, Stonehill, Wright \& Beekhuisen (1974), Scott Jr. e Martin (1975), Ferri e Jones (1979), Myers e Majluf (1984), Myers (1984), Titman e Wessels (1988), Allen (1995), Rajan e Zingales (1995), Kayo e Famá (1997) Jorge e Armada (2001), Perobelli e Famá (2002),e o de Brito, Corrar e Batistella (2007), utilizaram como variável dependente o endividamento geral e o endividamento de longo prazo. Enquanto no estudo de Perobelli e Famá (2003) analisou-se de modo individual o endividamento de longo prazo, e o estudo de Nakamura et al. (2007) analisaram o endividamento geral como variável dependente.

Estudos testaram o tamanho, medido pelo volume de vendas e/ou total de ativos e/ou número de empregados, como variável determinante da estrutura de capital.

No estudo de Remmers et al. (1974), a relação encontrada foi negativamente significativa. Já outros pesquisadores como Scott Jr. e Martin (1975), Ferri e Jones (1979), Titman e Wessels (1988), Rajan e Zingales (1995), Perobelli e Famá (2003), Brito, Corrar e Batistella (2007) e o de Nakamura et al. (2007) encontraram uma relação significativamente positiva entre o tamanho e a estrutura de capital. Porém, no estudo de Jorge e Armada (2001), as variáveis "número de empregados" e "volume de vendas" apontaram uma relação negativa, enquanto a variável "ativo total" apresentou uma relação positiva mas, no entanto, fraca devido ao seu resultado estar próximo de zero, do qual os mesmos ressaltaram que não houve relação positiva entre o tamanho e a estrutura de capital. Assim estabeleceu-se a seguinte hipótese:

\section{H1 - Existe uma relação positiva entre o tamanho e a estrutura de capital.}

Hla - Existe uma relação positiva entre o volume de vendas e o endividamento geral.

$H 1 b$ - Existe uma relação positiva entre o volume de vendas e o endividamento de longo prazo.

H1c - Existe uma relação positiva entre o número de empregados e o endividamento geral.

HId - Existe uma relação positiva entre o número de empregados e o endividamento de longo prazo.

Em relação à variável que representa a taxa de crescimento dos ativos, o estudo de Perobelli e Famá (2003), no contexto analisado do México, destacou-se uma relação negativa, conduzindo a ideia de que empresas em crescimento têm menos incentivo ao endividamento. Enquanto, diversos estudos como o de Toy, Stonehill, Remmers, Wright e Beekhuisen(1974) apontou uma relação positiva dessa variável aplicada como determinante da estrutura de capital, do qual corroboram com este resultado os achados de Titman e Wessels (1988), Thies e Klock (1992), Balakrishnan e Fox (1993) e Augusto (1996).

Já nos estudos de Jorge e Armada (2001), Brito, Corrar e Batistella (2007) e o de Nakamura et al. (2007), também foram encontradas uma relação positiva, mas analisando a relação entre a taxa de crescimento das vendas com a estrutura de capital. Ainda sobre esses estudos, salienta-se que os autores como Thies e Klock (1992) e Augusto (1996) analisaram a associação do crescimento com o endividamento a partir da Teoria de Pecking Order. Desta forma, determinou-se a seguinte hipótese:

\section{H2 - Existe uma relação positiva entre o crescimento e a estrutura de capital.}


H2a - Existe uma relação positiva entre o crescimento das vendas e o endividamento geral.

$H 2 b$ - Existe uma relação positiva entre o crescimento das vendas e o endividamento de longo prazo.

No que se refere à rentabilidade, diversos estudos analisaram a rentabilidade dos ativos, considerando que os estudos de Toy et al., (1974), Myers e Majluf (1984), Myers (1984), Titman e Wessels (1988), Thies e Klock (1992) e o de Jorge e Armada (2001) encontraram relação negativa entre a rentabilidade e a estrutura de capital, enquanto os estudos de Jensen (apud Rajan\& Zingales, 1995) encontraram uma relação positiva. Em relação à rentabilidade do patrimônio líquido, os estudos de Eid Junior (1996) e Soares e Procianoy (2000) destacaram uma relação negativa com a estrutura de capital, em virtude de que as empresas com maior alta retorno e lucratividade tendem a ser menos endividadas.

Já Perobelli e Famá (2002) encontraram analisando o caso brasileiro que, quanto maior a lucratividade, maior era o nível de endividamento das empresas, tendo desta forma uma relação positiva com a estrutura de capital, de modo que o mesmo resultado significativamente foi evidenciado pelos autores Perobelli e Famá (2003) analisado nos países da Argentina, Chile e México. Entretanto, considerando todo o contexto, formulou-se a seguinte hipótese:

\section{H3 - Existe uma relação negativa entre a rentabilidade e a estrutura de capital.}

H3a - Existe uma relação negativa entre a rentabilidade dos ativos e o endividamento geral.

$H 3 b$ - Existe uma relação negativa entre a rentabilidade dos ativos e o endividamento de longo prazo.

H3c - Existe uma relação negativa entre a rentabilidade do patrimônio e o endividamento geral.

H3d - Existe uma relação negativa entre a rentabilidade do patrimônio e o endividamento de longo prazo.

Quanto ao fator tipo do capital, Brito, Corrar e Batistella (2007) analisaram em seu modelo de análise das determinantes da estrutura de capital, a variável que destaca se a empresa de capital aberto ou capital fechado e seu resultado aponta uma relação negativa, de modo que, significativamente, o fato de a empresa ser de capital aberto e ter à disposição o financiamento por meio de emissão de ações não condiz como uma determinante da estrutura de capital das empresas. Assim, destaca-se a seguinte hipótese:

H4 - Existe uma relação negativa entre o tipo de capital e a estrutura de capital.

H4a - Existe uma relação negativa entre o tipo de capital e o endividamento geral.

$H 4 b$ - Existe uma relação negativa entre o tipo de capital e o endividamento de longo prazo.

Em se tratando de controle da organização, estabeleceu-se neste estudo a variável que representa se o controle da empresa nacional ou estrangeiro tem relação positiva com a estrutura de capital, com a finalidade de evidenciar se o controle pode influenciar no modo como é administrado o endividamento das empresas, partindo do pressuposto que o controle estrangeiro, no caso das empresas de tecnologia brasileiras, 
sofre com a influência dos países estrangeiros controladores. Assim, estabeleceu-se a seguinte hipótese:

\section{H5 - Existe uma relação positiva entre o controle e a estrutura de capital.}

H5a - Existe uma relação positiva entre o controle e o endividamento geral.

$H 5$ - Existe uma relação negativa entre o controle e o endividamento de longo prazo.

As hipóteses do grupo $\mathrm{H} 5$ foram estabelecidas ainda considerando os achados de Siqueira (1998), que teve por objetivo analisar as causas e consequências frente à concentração de propriedade de 278 empresas de capital aberto do Brasil, das quais ressaltou que o grau de concentração do controle acionário no país devido ao controle ser privado nacional, estatal ou estrangeiro sofrer influência, seja quanto à regulamentação do mercado, ao tamanho da firma e ainda em relação à estrutura de capital.

Desta forma, dado as hipóteses a serem testadas na pesquisa, passa-se ao próximo tópico que dará enfoque a metodologia a ser empregada na pesquisa.

\section{METODOLOGIA DA PESQUISA}

Para identificar os fatores determinantes da estrutura de capital das empresas brasileiras de tecnologia, realizou-se uma pesquisa descritiva com abordagem quantitativa por meio de pesquisa documental.

O destaque em relação à pesquisa descritiva se dá com base na discussão e descrição do desempenho das empresas, onde são considerados os aspectos bem como as características da amostra da pesquisa analisada (Neuendorf, 2002). Em relação aos procedimentos, a pesquisa classifica-se como documental, tendo em vista que ela utiliza-se de informações disponíveis nas demonstrações contábeis das empresas (Beuren, 2004). A pesquisa destaca-se ainda quanto à sua abordagem de problema como quantitativa, pois utiliza-se de variáveis mensuráveis para a aplicação de cálculos estatísticos (Richardson, 1989).

A presente população da pesquisa compreende as empresas dos setores de tecnologia brasileira listadas no ranking das "Melhores e Maiores de 2014", divulgado pela revista Exame. Deste modo, para a composição da amostra de 21 empresas selecionaram-se os setores de indústria digital, telecomunicações e comunicações, assim delimitou-se a amostra com base nas empresas que apresentavam disponibilização das variáveis utilizadas para a pesquisa, conforme discriminadas na Tabela 1.

Tabela 1 - Amostra da pesquisa

\begin{tabular}{l|l}
\hline Empresas & \multicolumn{1}{c}{ Setor (Revista Exame) } \\
\hline Infoglobo & Comunicações \\
RBS Participações & Comunicações \\
Zero Hora & Comunicações \\
Prodesp & Indústria Digital \\
BB Tecnologia e Serviços & Indústria Digital \\
\hline
\end{tabular}


Dataprev

Itautec

Positivo Informática

Diebold-SP

Semp Toshiba Informática

Stefanini

TecBan

Totvs

UOL

Algar Telecom

Autotrac

Oi

Star One

Telefônica

Telemont

Embratel
Indústria Digital

Indústria Digital

Indústria Digital

Indústria Digital

Indústria Digital

Indústria Digital

Indústria Digital

Indústria Digital

Indústria Digital

Telecomunicações

Telecomunicações

Telecomunicações

Telecomunicações

Telecomunicações

Telecomunicações

Telecomunicações

Fonte: Dados da pesquisa.

A coleta de dados ocorreu com base na seleção do ranking das "Melhores e Maiores" da revista Exame, que se torna relevante em virtude de conter dados das empresas de natureza jurídica de capital fechado, cujas informações são divulgadas pelas empresas em caráter voluntário.

Assim, os dados foram coletados de acordo com a disponibilidade de acesso às informações e, desta forma, resultou no período de análise, que compreende os anos de 2009 a 2013. As variáveis utilizadas na presente pesquisa estão representadas no Quadro 1.

\section{Quadro 1 - Variáveis analisadas}

\begin{tabular}{|l|l|l|l|}
\hline $\begin{array}{l}\text { Tipo de } \\
\text { Variáveis }\end{array}$ & Variáveis & Descrição & Autores \\
\hline \multirow{2}{*}{ Dependente } & ENDG & $\begin{array}{l}\text { Endividamento } \\
\text { Geral }\end{array}$ & $\begin{array}{l}\text { Jorge e Armada (2001); Perobelli } \\
\text { e Famá (2002); Brito, Corrar e } \\
\text { Batistella (2007); Nakamura et al. } \\
(2007) ;\end{array}$ \\
\cline { 2 - 4 } & ENDL & $\begin{array}{l}\text { Jorge e Armada (2001); Perobelli } \\
\text { e Famá (2002); Perobelli e Famá } \\
\text { Longo Prazo } \\
(2003) ; \text { Brito, Corrar e Batistella }\end{array}$ \\
\hline
\end{tabular}




\begin{tabular}{|c|c|c|c|}
\hline & VEND & $\begin{array}{l}\text { Vendas } \\
\text { (TAMANHO) }\end{array}$ & $\begin{array}{l}\text { Jorge e Armada (2001); Brito, } \\
\text { Corrar e Batistella (2007) }\end{array}$ \\
\hline & NEMP & $\begin{array}{l}\text { Número de } \\
\text { Empregados } \\
\text { (TAMANHO) }\end{array}$ & Jorge e Armada (2001) \\
\hline & TXVend & $\begin{array}{l}\text { Taxa de } \\
\text { crescimento das } \\
\text { vendas } \\
\text { (CRESCIMENTO) }\end{array}$ & $\begin{array}{l}\text { Jorge e Armada (2001); Brito, } \\
\text { Corrar e Batistella (2007); } \\
\text { Nakamura } \text { et al. }(2007) .\end{array}$ \\
\hline & ROA & $\begin{array}{l}\text { Rentabilidade dos } \\
\text { Ativos } \\
\text { (EBITDA/ATIVO } \\
\text { TOTAL) }\end{array}$ & $\begin{array}{l}\text { Jorge e Armada (2001); Nakamura } \\
\text { et al. }(2007)\end{array}$ \\
\hline Independentes & ROE & $\begin{array}{l}\text { Rentabilidade do } \\
\text { Patrimônio } \\
\text { (LUCRO LÍQ. / } \\
\text { PATRIMÔNIO } \\
\text { LÍQ.) }\end{array}$ & $\begin{array}{l}\text { Perobelli e Famá (2002); Perobelli } \\
\text { e Famá (2003) }\end{array}$ \\
\hline & CAP & $\begin{array}{l}1 \text { para capital aberto } \\
\text { e } 0 \text { para capital } \\
\text { fechado } \\
\text { (VÁRIAVEL } \\
\text { DUMMY) }\end{array}$ & Brito, Corrar e Batistella (2007) \\
\hline & CONTROL & $\begin{array}{l}1 \text { para controle } \\
\text { nacional e } 0 \text { para } \\
\text { controle estrangeiro } \\
\text { (VÁRIAVEL } \\
\text { DUMMY) }\end{array}$ & Não testada. \\
\hline
\end{tabular}

Fonte: Dados da pesquisa.

Inicialmente, necessita-se fazer o respaldo em relação ao ativo total do ano de 2010, que não estava disponível na base de dados da Revista Exame, dificultando o acesso a essa informação da amostra. Desta forma, para não prejudicar a pesquisa, a variável de desempenho econômico-financeiro ROA, que se refere ao retorno dos ativos no ano base de 2010, não foi evidenciada no modelo econométrico. Para os demais anos (2009, 2011, 2012 e 2013), a variável ROA foi analisada junto com as demais variáveis representadas no Quadro1.

A definição das variáveis utilizadas no presente estudo buscou envolver as variáveis que pudessem contribuir para explicar os fatores determinantes do endividamento das empresas brasileiras de tecnologia, considerando os indicadores que são representados pelas demonstrações contábeis e financeiras padronizadas pelas empresas.

Deste modo, para análise das variáveis apresentadas no Quadro 1, empregou-se a técnica estatística de análise de dados em painel que, de acordo com Fávero, Belfiore, Silva e Chan (2009), contribui para a evidenciação das relações existentes entre um 
grupo de variáveis métricas ou dummies em relação a uma variável dependente. Para tal, utilizou-se o software STATA® para aplicação da referida técnica de análise multivariada dos dados.

\section{ANÁLISE DOS RESULTADOS}

Neste tópico, apresentam-se os resultados obtidos a partir da pesquisa realizada, com o objetivo de identificar os fatores determinantes da estrutura de capital de empresas brasileiras de tecnologia, por meio da aplicação de dados em painel realizada a partir do software STATA®.

Para determinar qual o modelo a ser seguido para apresentação da análise, primeiramente aplicou-se o teste de Breusch-Pagan e de Hausman, numa amostra de empresas brasileiras, cujos resultados estão apresentados na Tabela 2.

Tabela 2 - Teste LM de Breusch-Pagan Brasil

\begin{tabular}{l|l|l}
\hline Variáveis & Var & Sd=sqrt (Var) \\
\hline ENDG & 333.7968 & 18.27011 \\
\hline E & 75.49238 & 8.688635 \\
\hline U & 200.3837 & 14.15569 \\
\hline Test Var(u) & 0 & \multicolumn{2}{|l}{} \\
\hline Chi2 & $\mathbf{3 0 . 4 7}$ & Sd=sqrt (Var) \\
\hline Prob>Chi2 & 0.0000 & 16.80036 \\
\hline Variáveis & Var & 8.236297 \\
\hline ENDLP & 282.2521 & 17.49012 \\
\hline E & 67.83659 & \\
\hline U & 305.9041 & \\
\hline Test Var(u) & 0 & \\
\hline Chi2 & $\mathbf{6 0 . 8 3}$ & \\
\hline Prob>Chi2 & 0.0000 &
\end{tabular}

Fonte: Dados da pesquisa.

Conforme demonstrado na Tabela 2, testa-se que a hipótese nula que indica que não existe variância no erro ocorrido do efeito específico (sigma $u=0$ ) foi rejeitada, assim este resultado indica que deve ser utilizado para fins de análise o Método de Efeito Aleatório, nos dois modelos rodados, sendo do ENDG (endividamento geral) e no ENDLP (endividamento de curto prazo).

Passados os testes para a identificação do modelo de regressão linear dos dados em painel a ser utilizado, que determinou o uso do Modelo de Efeitos Aleatórios para 
análise das empresas brasileiras de tecnologia. Assim, o resultado dos dados em painel em relação ao ENDG (endividamento geral) é retratado na Tabela 3.

Tabela 3 - Modelo de Efeitos Aleatórios quanto ao Endividamento Geral.

\begin{tabular}{|c|c|c|c|c|}
\hline Variáveis & Coeficiente & Erro Padrão & $\mathbf{Z}$ & $\mathbf{P}>|\mathbf{Z}|$ \\
\hline VEND & .1202203 & .1397721 & 0.86 & 0.390 \\
\hline NEMP & -.0389772 & .0390776 & -1.00 & 0.319 \\
\hline TXVend & .1334165 & .0785208 & 1.70 & 0.089 \\
\hline$\overline{\mathrm{ROA}}$ & -46.35452 & 14.81405 & -3.13 & 0.002 \\
\hline ROE & -1.92007 & 2.363228 & -0.81 & 0.417 \\
\hline$\overline{\mathrm{CAP}}$ & -5.849935 & 8.752454 & -0.67 & 0.504 \\
\hline CONTROL & 18.03938 & 9.339135 & 1.93 & 0.053 \\
\hline Cons. & 50.41561 & 8.937176 & 5.62 & 0.000 \\
\hline Rho & .72635399 & & & \\
\hline $\mathbf{R}^{2}$ within & 0.3505 & & & \\
\hline $\mathbf{R}^{2}$ between & 0.0480 & & & \\
\hline $\mathbf{R}^{2}$ overvall & 0.0879 & & & \\
\hline $\begin{array}{ll}\mathrm{N}^{\mathrm{o}} & \mathrm{de} \\
\text { Observações } & \end{array}$ & 84 & & & \\
\hline
\end{tabular}

Fonte: dados da pesquisa.

Os resultados da Tabela 3 demostraram que o poder explicativo do modelo econométrico representado pelo $\mathrm{R}^{2}$ foi de $35,05 \%$, indicando que as variáveis independentes que representam o tamanho (AT, VEND e NEMP), o crescimento (TXVend) e o desempenho econômico e financeiro (ROA e ROE), bem como se o capital é abeto ou fechado, ou ainda se o controle for nacional ou estrangeiro explica a variável dependente endividamento geral (ENDG) na proporção de 35,05\%, sendo o restante atribuído a outros fatores e eventos. Já em relação $\mathrm{R}^{2}$ overvall, que representa $\mathrm{o}$ poder explicativo $\mathrm{R}^{2}$ ajustado do modelo, apresentou um valor considerado baixo de 8,79\% no período analisado de 2009 a 2013.

Em relação às variáveis pressupostas para explicar o endividamento de longo prazo, encontram-se destacados os resultados dos dados em painel na Tabela 4.

Tabela 4 - Modelo de Efeitos Aleatórios quanto ao Endividamento de Longo Prazo.

\begin{tabular}{l|l|l|l|l}
\hline Variáveis & Coeficiente & Erro Padrão & $\mathbf{Z}$ & $\mathbf{P}>|\mathbf{Z}|$ \\
\hline VEND & -.0761426 & .1307458 & -0.58 & 0.560 \\
\hline
\end{tabular}




\begin{tabular}{l|l|l|l|l}
\hline NEMP & -.0091964 & .0359036 & -0.26 & 0.798 \\
\hline TXVend & -.0382502 & .0691421 & -0.55 & 0.580 \\
\hline ROA & -35.62904 & 13.49918 & -2.64 & 0.008 \\
\hline ROE & -.1877983 & 2.093297 & -0.09 & 0.929 \\
\hline CAP & -1.882976 & 9.659054 & -0.19 & 0.845 \\
\hline CONTROL & 2.012852 & 10.12724 & 0.20 & 0.842 \\
\hline Cons. & 30.94007 & 9.627454 & 3.21 & 0.001 \\
\hline Rho & .8184929 & & & \\
\hline $\mathbf{R}^{2}$ within & 0.2608 & 0.0056 & & \\
\hline $\mathbf{R}^{2}$ between & 0.0066 & & \\
\hline $\mathbf{R}^{\mathbf{2}}$ overvall & 84 & & \\
\hline $\begin{array}{l}\mathbf{N}^{\mathbf{0}} \\
\text { Observações }\end{array}$ & & & \\
\hline
\end{tabular}

Fonte: dados da pesquisa.

A Tabela 4 destaca que variáveis independentes que representam o tamanho (AT, VEND e NEMP), o crescimento (TXVend) e o desempenho econômico e financeiro (ROA e ROE), o capital e o controle explicam o endividamento de longo prazo em 26,08\%, dado pelo $\mathrm{R}^{2}$ do modelo econométrico. Em se tratando do $\mathrm{R}^{2}$ overvall, destacou-se um poder explicativo ajustado do modelo praticamente insignificante de $0,66 \%$ no período analisado de 2009 a 2013. Assim, passamos as discussões das hipóteses no próximo subtítulo.

Os resultados atrelado às variáveis que representam o tamanho da empresa, sendo elas VEND e NEMP, apresentou coeficientes positivo para VENDde .1202203 não significativo quanto ao ENDG e coeficiente negativo de -.0761426 não significativo para o ENDLP. E em se tratando dos coeficientes negativos relacionados ao NEMP foram de -.0389772 e -.0091964 , resultaram em dados não significativos tanto para o ENDG quanto para o ENDLP determinantes da estrutura de capital.

Desta forma, este resultado indica quanto maior o tamanho da empresa, menor será o volume de endividamento, seja ENDG ou ENDLP, demonstrando que o tamanho melhora a estrutura de capital das empresas.

Quanto a variável utilizada para medir o crescimento, a variável TXVend aponta um coeficiente positivo de .1334165 não significativo em relação ao ENDG, que o crescimento das vendas é influenciado positivamente no endividamento geral. Entretanto, este resultado quando analisado em relação ao endividamento de longo prazo demonstra-se com coeficiente negativo de -.0382502 não significativo. Deste modo, a taxa de crescimento das vendas influencia positivamente na estrutura de capital das empresas, revelando que estes achados podem estar relacionados à gestão da empresa ser mais voltada ao planejamento de curto prazo do que com o de longo prazo.

No que tange as variáveis que representam a rentabilidade por meio do ROA e ROE, os dos coeficientes negativos apurados pelo ROA de -46.35452 e -35.62904 
quanto ao ENDG e ao ENDLP foram significativos e os coeficientes negativos do ROE de -1.92007 e -.1877983, em relação ao ENDG e ao ENDLP, que não resultou em significância estatística, evidenciam que há relação negativa entre a rentabilidade e a estrutura de capital. Estes achados revelam que, quanto maior a rentabilidade das empresas menor será a propensão ou incentivo ao endividamento geral ou de longo prazo.

Em relação a variável analisada que se refere ao tipo de capital, demonstrado pela variável CAP, os resultados dos coeficientes de -5.849935 e -1.882976 para o ENDG e o ENDLP não significativos encontrados pelo modelo econométrico, salientam que as empresas que negociam na bolsa não se diferem das empresas que não negociam na bolsa, indicando que, mesmo com as empresas de capital aberto podendo financiar-se por meio da emissão de ações, as mesmas não apresentam menor nível de endividamento ou propensão/incentivo ao endividamento do que as empresas de capital fechado.

Quanto à variável que representa o tipo de controle (CONTROL), as empresas que apresentam controle acionário nacional se diferem das empresas que têm o controle acionário em poder de países estrangeiros. Deste modo, os achados do coeficiente positivo respectivamente de 18.03938 e 2.012852 para o ENDG e o ENDLP, indicam que controle acionário é um fator positivo determinante da estrutura de capital das empresas, que pode variar conforme a cultura do país controlador.

\subsection{Discussão das Hipóteses de Pesquisa}

Em relação à discussão das hipóteses do grupo H1, que prediz que existe uma relação positiva entre o tamanho e a estrutura de capital, esperava-se uma relação positiva entre o volume de vendas e o endividamento geral, resultado que foi evidenciado pela hipótese H1a que foi aceita, porém que não apresentou-se significativa, mas corroborando com os achados de Scott Jr. e Martin (1975), Ferri e Jones (1979), Titman e Wessels (1988), Rajan e Zingales (1995), Brito, Corrar e Batistella (2007) e o de Nakamura et al. (2007), que destacavam uma relação positivamente significativa, predizendo que, quanto maior o tamanho, melhor a estrutura de capital das empresas.

Quanto à hipótese $\mathrm{H} 1 \mathrm{~b}$, esperava-se também uma relação positiva entre o volume de vendas com o endividamento de longo prazo, o resultado apontou que esta relação foi negativa. Porém não significativa ao nível de $95 \%$ de confiança, denotandose assim a rejeição da hipótese $\mathrm{H} 1 \mathrm{~b}$, corroborando com os achados de Remmers et al. (1974) e de Jorge e Armada (2001), mais contradizendo os resultados encontrados por Scott Jr. e Martin (1975), Ferri e Jones (1979), Titman e Wessels (1988), Rajan e Zingales (1995), Perobelli e Famá (2003) e Brito, Corrar e Batistella (2007), que previam uma relação positiva com a estrutura de capital.

Em se tratando da hipótese $\mathrm{H} 1 \mathrm{c}$, da qual se esperava uma relação positiva entre o número de empregados e o endividamento geral, o resultado obtido demonstrou que existe uma relação negativa. Contudo os dados não foram suficientemente significativos. Desta forma, a H1c foi rejeitada, corroborando com os achados de Jorge e Armada (2001), destacando que, quanto maior o número de empregados, menor o endividamento.

A hipótese H1d previa a existência de uma relação positiva entre o número de empregados e o endividamento de longo prazo. Entretanto, evidenciou-se uma relação 
negativa entre as variáveis, rejeitando-se a hipótese H1d, corroborando os resultados de Jorge e Armada (2001).

Assim, no que compreende ao tamanho e a estrutura de capital, os resultados evidenciados destacam que o tamanho influencia na estrutura de capital das empresas, todavia que a relação existente entre o tamanho e a estrutura de capital é negativa.

No que tange às hipóteses do grupo $\mathrm{H} 2$, que previa a existência de uma relação positiva entre o crescimento e a estrutura de capital, ressalta-se que a hipótese H2a foi aceita, em virtude de demonstrar uma relação positiva entre a taxa de crescimento das vendas e o endividamento geral, corroborando com os achados dos estudos de Jorge e Armada (2001), Brito, Corrar e Batistella (2007) e o de Nakamura et al. (2007).

No que se refere à hipótese $\mathrm{H} 2 \mathrm{~b}$, a hipótese foi rejeitada, devido a mesma ter resultado em uma relação negativa e não significativa entre a taxa de crescimento das vendas e o endividamento de longo prazo, confrontado assim os resultados da pesquisa de Jorge e Armada (2001) e de Brito, Corrar e Batistella (2007).

Desta forma, salienta-se que o crescimento não apresenta uma relação positiva com a estrutura de capital, indo contra aos demais resultados apontados por Toy et al. (1974), de Titman e Wessels (1988), Thies e Klock (1992), Balakrishnan e Fox (1993), Augusto (1996), Jorge e Armada (2001) e de Brito, Corrar e Batistella (2007), mas corroborando com os achados do estudo de Perobelli e Famá (2003), que evidenciaram, no contexto do México, uma relação negativa, enfatizando que empresas que estão passando por um período de crescimento têm menos proporção ou incentivo ao endividamento.

Os resultados para o grupo de hipótese $\mathrm{H} 3$ referiam-se ao fato de que existe uma relação negativa entre a rentabilidade e a estrutura de capital, assim constatou-se para a hipótese $\mathrm{H} 3 \mathrm{a}$ e $\mathrm{H} 3 \mathrm{~b}$, que existe uma relação negativamente significativa entre o retorno dos ativos com o endividamento geral e o endividamento de longo prazo. Assim, as hipóteses H3a e H3b foram aceitas e confirmam os achados de Toy et al., (1974), Myers e Majluf (1984), Myers (1984), Titman e Wessels (1988), Thies e Klock (1992) e o de Jorge e Armada (2001) e contradiz o resultado evidenciado por Jensen (apud Rajan \& Zingales, 1995), que encontraram uma relação positiva entre a rentabilidade e a estrutura de capital.

Quanto a hipótese $\mathrm{H} 3 \mathrm{c}$, a qual estabelecia-se uma relação negativa entre o retorno do patrimônio e o endividamento geral, os resultados apontaram a aceitação da hipótese H3c, corroborando com os resultados evidenciados por Eid Junior (1996) e Soares e Procianoy (2000), tendo em vista que empresas com maior retorno e lucratividade tendem a contrair menos dividas, indo contra os resultados evidenciados por Perobelli e Famá (2002), que enfatizavam que quanto maior a lucratividade maior o endividamento das empresas.

Em se tratando da hipótese $\mathrm{H} 3 \mathrm{~d}$, que predizia a existência de uma relação negativa entre a rentabilidade do patrimônio líquido com o endividamento de longo prazo, os resultados destacaram que esta relação é realmente negativa, porém os dados não foram significativos, entretanto aceita-se a hipótese $\mathrm{H} 3 \mathrm{~d}$, corroborando com os achados de Eid Junior (1996) e Soares e Procianoy (2000) e confrontando os resultados da pesquisa de Perobelli e Famá (2002) e de Perobelli e Famá (2003).

Neste contexto, os resultados demonstram que existe uma relação negativa entre a rentabilidade e a estrutura de capital, resultados destacados também nas pesquisas de Toy et al., (1974), Myers e Majluf (1984), Myers (1984), Titman e Wessels (1988), 
Thies e Klock (1992), Eid Junior (1996), Soares e Procianoy (2000) e de Jorge e Armada (2001).

No que tange ao grupo de hipóteses $\mathrm{H} 4$, que preconiza a existência de uma relação negativa entre o tipo de capital e a estrutura de capital, destaca-se que a hipótese $\mathrm{H} 4 \mathrm{a}$ e H4b foram aceitas, indicando que existe uma relação negativa entre o fator tipo de capital, seja aberto ou fechado, com a estrutura de capital. Entretanto, os dados não foram significativos. Porém, estes resultados corroboram com a pesquisa de Brito, Corrar e Batistella (2007), que enfatizaram que o fato de a empresa negociar ações na bolsa de valores como fonte de obtenção de financiamento não impacta como uma variável determinante da estrutura de capital das empresas.

Em se tratando do último grupo de hipótese H5, o mesmo referia-se que existe uma relação positiva entre o controle e a estrutura de capital. Assim, a hipótese H5a e $\mathrm{H} 5 \mathrm{~b}$ foram aceitas, demonstrando que essa relação é positiva, mas não foi dada como significativa. Este resultado indica que o grau de concentração do controle acionário é um fator determinante da estrutura de capital das empresas, em virtude que o controle sofre influência do país, seja nacional ou estrangeiro. Isso corrobora com a preposição destacada por Siqueira (1998), que ainda salientou que esse controle também é influenciado pelo controle quando privado ou estatal.

Desta forma, evidencia-se os resultados gerais encontrados para as hipóteses de pesquisa, enfatizando que o tamanho da empresa não apresenta relação positiva com a estrutura de capital, mas que a taxa de crescimento das vendas apresenta relação positiva com a estrutura de capital no curto prazo, considerando que, no longo prazo, a hipótese foi rejeitada. Quanto à rentabilidade, os achados demonstraram uma relação negativa com a estrutura de capital, assim como o fator de tipo de capital, mas que, quando se trata do controle, o mesmo influencia positivamente na estrutura de capital.

\section{CONCLUSÕES E RECOMENDAÇÕES}

As empresas de tecnologia são peças extremamente importantes para $o$ estabelecimento do desenvolvimento de um país, em virtude que auxiliam no desenvolvimento da infraestrutura tecnológica, bem como na competitividade no comércio mundial. Dessa forma, o presente estudo teve como objetivo identificar os fatores determinantes da estrutura de capital de empresas brasileiras de tecnologia.

Assim, os resultados da pesquisa destacam que o tamanho da empresa não apresenta relação positiva com a estrutura de capital, tendo em vista que, quanto maior o tamanho, menor o nível de endividamento e, consequentemente, melhor a estrutura de capital da empresa, mas que, no entanto, o volume de vendas influencia positivamente no endividamento geral das empresas.

Em relação ao crescimento, destaca-se como evidenciado que o volume de vendas influencia no endividamento geral. O crescimento desta taxa de vendas também é influenciado positivamente no endividamento geral, mas não no endividamento de longo prazo, que pode ser devido à gestão da empresa trabalhar mais no curto prazo do que com o planejamento das vendas para o longo prazo e, assim, confirmar que a taxa de crescimento das vendas influencia positivamente na estrutura de capital das empresas no curto prazo. 
Ao se tratar da rentabilidade, os resultados demonstram que existe uma relação negativa com a estrutura de capital, predizendo que, quanto maior a rentabilidade das empresas, menor a propensão ou incentivo ao endividamento.

No que refere-se ao capital, os achados retratam que, mesmo que a empresa tenha a possibilidade de se financiar por meio da negociação de ações na bolsa de valores, as mesmas não apresentam menor propensão ao endividamento, quando comparadas com as empresas de capital fechado.

Finalizando, destaca-se quanto ao controle que as empresas que têm concentração de controle acionário sob gerência de países estrangeiros ou nacionais é um fator positivamente determinante da estrutura de capital das empresas.

Desta forma, este estudo contribuiu na evidenciação dos determinantes da estrutura de capital das empresas de tecnologia, que foram incluídas, além de variáveis de desempenho econômico-financeiro, as variáveis que representam o tipo de capital e o tipo de controle, devido ao fato de que grande parte das empresas de tecnologia que opera no país é de capital fechado e controlada por países estrangeiros, os quais apresentam grande importância, tanto para o desenvolvimento tecnológico quanto para o desenvolvimento econômico e financeiro do Brasil.

A presente pesquisa contribuiu ainda para o entendimento mais detalhado do comportamento dos determinantes da estrutura de capital das empresas, juntamente com as pesquisas desenvolvidas em torno da área de finanças relacionadas a estrutura de capital. Assim como também os achados desta pesquisa contribuem para o desenvolvimento de informações para novas pesquisas.

Como limitações da pesquisa destacam-se a indisponibilidade de informação quanto ao ativo total do ano 2010, que não estavam disponibilizados na base da Revista Exame, bem como não se conseguiu localizar todos os ativos totais das empresas por meio da procura nos relatórios de administração que também foram consultados, quando disponíveis.

Como sugestão para a realização de trabalhos futuros, recomenda-se o uso de outras técnicas de análise estatística dos dados, bem como aplicação deste estudo em outros setores econômicos para se obter mais evidências quanto à estrutura de capital das empresas, sejam brasileiras ou estrangeiras, que podem ainda sofrer influência de outros indicadores de desempenho econômico-financeiro.

\section{REFERÊNCIAS}

Anthony, R. N., Govindarajan, V. (2001). Sistemas de controle gerencial. São Paulo: Atlas.

Assaf Neto, A. (2012). Finanças corporativas e valor. 6. ed. São Paulo: Atlas.

Augusto, M. A. G. (1996). Determinantes da estrutura de capital das empresas da indústria transformadora portuguesa. 1996. Dissertação (Mestrado em Economia) Faculdade de Economia, Universidade de Coimbra, Coimbra.

Balakrishnan, S., \& Fox, I. (1993). Asset specificity, firm heterogeneity and capital structure. Strategic Management Journal, 14 (1), 3-16. 
Bastos, D. D., \& Nakamura, W. T. (2009). Determinantes da estrutura de capital das companhias abertas no Brasil, México e Chile no período 2001-2006. Revista Contabilidade \& Finanças-USP, 20(50), 75-94.

Beuren, I. M. (2003). Como elaborar trabalhos monográficos em contabilidade: teoria e prática. São Paulo: Atlas.

Borba, P. R. F. (2005). Relação entre desempenho social corporativo e desempenho financeiro de empresas no Brasil. 2005. 127 f. Dissertação (Mestrado em Administração) - Programa de Pós Graduação em Administração - Faculdade de Economia, Administração e Contabilidade, Universidade de São Paulo, São Paulo.

Brealey, R. \& Myers, S. C. (2006). Principles of corporate finance. 8. ed. Nova York: McGraw-Hill.

Brito, G. A. S., Corrar, L. J., \& Batistella, F. D. (2007). Fatores determinantes da estrutura de capital das maiores empresas que atuam no Brasil. Revista Contabilidade e Finanças USP, (43), 9-19.

Camargos, M. A., \& Barbosa, F. V. (2003). Teoria e evidência da eficiência informacional do mercado de capitais brasileiro. Caderno de Pesquisas em Administração, 10(1).

Damodaran, A. (1997). Avaliação de investimento: ferramentas e técnicas para avaliação do valor de qualquer ativo. Rio de Janeiro: Qualitymark.

David, M., Nakamura, W. T., \& Bastos, D. D. (2009). Estudo dos modelos trade-off e pecking order para as variáveis endividamento e payout em empresas brasileiras (20002006). Revista de Administração Mackenzie,10(6).

Eld Junior, W. (1996). Custo e estrutura de capital: o comportamento das empresas brasileiras. Revista de Administração de Empresas, 36(4), 51-59.

Fama, E. F. (1970). Efficient capital markets: A review of theory and empirical work*. The Journal of Finance, 25(2), 383-417.

Fama, E. F. (1998). Value versus Growth: The International Evidence. The Journal of Finance, 8(6).

Fávero, P. L.; Belfiore, P.; Silva, F. L. Da; Chan, B. L. (2009). Análise de dados: modelagem multivariada para tomada de decisões. Rio de Janeiro: Elsevier.

Ferri, M. G., \& Jones, W. H. (1979). Determinants of financial structure: A new methodological approach. The Journal of Finance, 34(3), 631-644.

Ferreira, C. C., Macedo, M. A. S. (2011). Desempenho Financeiro de Curto Prazo no Setor Brasileiro de Telecomunicações. Revista Pretexto, 12(4).

Fischmann, A. A., \& Zilber, M. A. (2009). Utilização de indicadores de desempenho para a tomada de decisões estratégicas: um sistema de controle. Revista de Administração Mackenzie, 1(1).

Gitman, L. J., \& Joehnk, M. D. (2005). Princípios de investimentos. Pearson Addison Wesley.

Groppelli, A. A., Nikbakht, E. (2006). Administração financeira. 2 ed. São Paulo: Saraiva. 
Hajj, Z. S. E. (2005). Evolução e desempenho dos bancos durante o Plano Real.Tese (Doutorado em Controladoria e Contabilidade) - Programa de Pós-Graduação em Ciências Contábeis da Universidade de São Paulo, São Paulo, SP.

Helfert, E. (2000). Técnicas de análise financeira: um guia prático para medir o desempenho dos negócios. 9. ed. Porto Alegre: Bookmark.

Jensen, J., Menezes-Filho, N., \& Sbragia, R. (2004). Os determinantes dos gastos em P\&D no Brasil: uma análise com dados em painel. Estudos Econômicos, 34(4), 661691.

Jones, C. I., \& Williams, J. C. (2000). Too much of a good thing? The economics of investment in R\&D. Journal of Economic Growth, 5(1), 65-85.

Jorge, S., \& Armada, M. J. D. R. (2001). Factores determinantes do endividamento: uma análise em painel. Revista de Administração Contemporânea, 5(2), 9-31.

Lach, S., \& Schankerman, M. (1989). Dynamics of R \& D and Investment in the Scientific Sector. The Journal of Political Economy, 880-904.

Lang, L., Ofek, E.\& Stulz, R. M. (1996).Leverage, investment, and firm growth. Journal of financial Economics, v. 40, n. 1, p. 3-29.

Macedo, M. A. S., Santos, R. M.\& Silva, F. F. (2006). Desempenho organizacional no setor bancário brasileiro: uma aplicação da análise envoltória de dados. RAM. Revista de Administração Mackenzie, 7(1), 11-44.

Marcovitch, J., Santos, S. A., \& Dutra, I. (1986). Criação de empresas com tecnologias avançadas: as experiências do PACTo/IA-FEA-USP. Revista de Administração da Universidade de São Paulo, 21(2).

Matarazzo, D. C. (2008). Análise financeira de balanços: abordagem básica e gerencial. 6. ed. São Paulo: Atlas.

Martinez, A. L. (1999). Buscando o valor intrínseco de uma empresa: revisão das metodologias de avaliação de negócios. Associação Nacional de Pós Graduação Em Administração, 23.

Miller, M. H. (1977). Debt and Taxes*. The Journal of Finance, 32(2), 261-275.

Miltersteiner, M. R. (2003). A Validade estatística do uso de índices fundamentalistas no mercado de capitais brasileiro: um estudo aplicado ao setor bancário. 2003. $74 \mathrm{f}$. Dissertação (Mestrado em Engenharia de Produção), - Programa de Pós Graduação em Engenharia de Produção - Universidade Federal de Santa Catarina, Florianópolis.

Modigliani, F., \& Miller, M. H. (1958). The cost of capital, corporation finance and the theory of investment. The American Economic Review, 261-297.

Modigliani, F., \& Miller, M. H. (1963). Corporate income taxes and the cost of capital: a correction. The American Economic Review, 433-443.

Myers, S. C. (1977). Determinants of corporate borrowing. Journal of Financial Economics, 5(2), 147-175.

Myers, S. C. (1984). The capital structure puzzle. The Journal of Finance,39(3), 574592. 
Myers, S. C., \& Majluf, N. S. (1984). Corporate financing and investment decisions when firms have information that investors do not have. Journal of Financial Economics, 13(2), 187-221.

Myers, S. C. (2001). Capital structure. Journal of Economic Perspectives, 81-102.

Nakamura, W. T., Martin, D. M. L., Forte, D., Carvalho Filho, A. F., Costa, A. C. F. D., \& Amaral, A. C. D. (2007). Determinantes de estrutura de capital no mercado brasileiro: análise de regressão com painel de dados no período 1999-2003. Revista Contabilidade \& Finanças, 18(44), 72-85.

Neuendorf, K. A. (2002). The content analysis guidebook. 2 ed. London: Sage Publications.

Perobelli, F. F. C., \& Famá, R. (2002). Determinantes da estrutura de capital: aplicação a empresas de capital aberto brasileiras. Revista de Administração da Universidade de São Paulo, 37(3).

Perobelli, F. F. C., \& Famá, R. (2003). Fatores determinantes da estrutura de capital para empresas latino-americanas. Revista de Administração Contemporânea, 7(1), 9-35.

Rajan, R. G., \& Zingales, L. (1995). What do we know about capital structure? Some evidence from international data. The journal of Finance, 50(5), 1421-1460.

Remmers, L., Stonehill, A., Wright, R., \& Beekhuisen, T. (1974). Industry and size as debt ratio determinants in manufacturing internationally. Financial Management, 24-32.

Resende, L. L. 2012. Análise do desempenho econômico-financeiro: um estudo ex ante e ex post diante da fusão Itaú Unibanco. 2012. 155 f. Dissertação (Mestrado em Contabilidade) - Programa de Pós-graduação e Pesquisas em Contabilidade e Controladoria, Universidade Federal de Minas Gerais, Belo Horizonte.

Richardson, R. J. (1989). Pesquisa social: métodos e técnicas. 2. ed. São Paulo: Atlas.

Scott Jr, D. F., \& Martin, J. D. (1975). Industry influence on financial structure. Financial Management, 67-73.

Shyam-Sunder, L., \& C Myers, S. (1999). Testing static tradeoff against pecking order models of capital structure. Journal of financial economics,51(2), 219-244.

Silva, T. (2012). Risco positivo na atividade de crédito que otimiza o desempenho econômico-financeiro de cooperativas de crédito. 2012. 203 f.Tese (Doutorado em Ciências Contábeis e Administração) - Programa de Pós-Graduação em Ciências Contábeis da Universidade Regional de Blumenau, Blumenau, SC.

Siqueira, T. V. (1998). Concentração da propriedade nas empresas brasileiras de capital aberto. Revista do BNDES, (10).

Soares, K., \& Procianoy, J. L. (2000). O perfil de endividamento das empresas negociadas na Bolsa de Valores de São Paulo após o Plano Real. In: Encontro Anual da Anpad, 24.

Thies, C. F., \& Klock, M. S. (1992). Determinants of capital structure. Review of Financial Economics, 1(2), 40-52.

Titman, S., \& Wessels, R. (1988). The determinants of capital structure choice. The Journal of Finance, 43(1), 1-19.

Toy, N., Stonehill, A., Remmers, L., Wright, R., \& Beekhuisen, T. (1974). A comparative international study of growth, profitability, and risk as determinants of 
corporate debt ratios in the manufacturing sector. Journal of Financial and Quantitative Analysis, 9(05), 875-886.

Vieira, E. F. S., \& Novo, A. J. (2010). A estrutura de capital das PME: evidência no mercado português, Revista Estudos do ISCA, 4(2).

Yang, C. C. (2012). The effect of environmental management on environmental performance and firm performance in Taiwanese maritime firms. International Journal of Shipping and Transport Logistics, 4(4), 393-407.

Zilber, M. A.\& Fischmann, A. A. (2002). Competitividade e a importância de indicadores de desempenho: utilização de um modelo de tendência. Encontro da Associação Nacional dos Programas de Pós-Graduação em Administração, 26. 